\title{
Design and Realization of FERP Experimental Teaching Platform Based on Synergy Innovation
}

\author{
Jian Ruan \\ Department of Finance, \\ Guangdong University of Finance \\ Guangzhou 510521, China \\ ruanjian1982@163.com
}

\author{
Xiaoyan Wang \\ Academic Administration \\ Guangdong University of Finance \\ Guangzhou 510521, China
}

\author{
Yan $\mathrm{Hu}$ \\ Department of Finance, \\ Guangdong University of Finance \\ Guangzhou 510521, China
}

\begin{abstract}
How to build a highly emulational, open and comprehensive teaching platform has been a main concern of experimental teaching in universities for a long time. After indepth study of the law of experimental teaching development, the current situation and the developing trend of financial industry, GDUF developed the FERP Experimental Teaching Platform. Different from others, this platform creatively utilizes the resources of university-enterprise synergy innovation in order to cultivate high-quality applied talents who possess both multidisciplinary knowledge and innovative ability. It is proved that platform based on synergy innovation can help experimental teaching to achieve resources complementation between universities and enterprises, generating a win-win situation and promoting the platform construction in a high-level and sustainable way.
\end{abstract}

Keywords-synergy innovation; FERP experimental teaching platform; applied talents

\section{INTRODUCTION}

As an important carrier of applied-style talents cultivation, experimental teaching platform is vital to improve both practical and innovative ability of students. At the early stage, the construction of university experimental teaching platform mainly relied on software companies. Universities used to purchase teaching software products from software companies in the market directly. This market-oriented way promotes the construction of university experimental teaching platform effectively. It builds a basic experimental teaching system that is progressive and has a hierarchical structure from the elementary part to the comprehensive part and to the designing and innovative part [1]. Moreover, thanks to the advantages of professional information technology of software companies, it realizes the combination of traditional experiments and modern technology, promoting the sharing, electronization and virtualization of experimental teaching resources [2, 3]. However, there exist some problems at the same time. First of all, standardized experimental teaching software often ignores the individual need of characteristic majors of different universities, so it cannot meet the need of different plans of talents cultivation. Secondly, companies are short of in-depth study on experimental teaching activities. Therefore, the software they develop cannot fit the experimental projects, experimental teaching contents and experimental teaching organization well. Thirdly, the maintenance cost of experimental teaching software is relatively high. The cost includes not only money but also human resources. Once software breaks down, it is very likely to become useless "zombie" software if the technological service offered by the software companies expires and the university lacks corresponding support. Therefore, how to construct a characteristic experimental teaching platform with the consideration of university-running orientation and talents cultivation goal and how to realize the sustainable development of experimental teaching construction have become urgent problems in practice. Consequently, we constructed Financial Enterprise Resource Planning (FERP) experimental teaching platform based on the idea of synergy innovation, including FERP software system and sand table, to realize the simulation of banking management and business process.

\section{THE CONNOTATION OF SYNERGY INNOVATION}

Study on synergy innovation starts from inner-enterprise synergy initially. Ansoff (1965) is the first one to come up with the concept of "synergy" when he did research on the problems of corporation diversification, and he studied the synergy problem between each business division within the corporation [4]. Srivastava and Gnyawali (2011) think that if corporations want to gain technological advantages, it is necessary to cooperate technological and inner resources with other innovative factors in order to realize breakthrough innovation [5]. The subject of inner synergy innovation is the organization itself, and its realization depends on the interaction of inner factors. Due to the limited restriction on inner resources, researchers consider synergy innovation the source and power to realize sustainable development of corporation [6]. With the focus moving to the interaction of the organization and other subjects, they extend the range of 
synergy subjects from inner organization to betweenorganizations, including supply chain companies, other related companies, research institutions, universities, intermediary agents and government organizations [7, 8]. And they define synergy innovation as knowledge value-added-centered, highly integrated innovative organization mode carried by corporations, government, knowledge producing organizations, intermediary agents and users to realize major innovation [9]. The innovative motivation and demand of corporations in traditional strategic alliances will decline with time. With the completion of missions and realization of goals, the alliances will dismiss, and the synergy innovation will terminate [10]. Different from traditional strategic alliances, the synergy innovation puts an emphasis on applying the idea of synergy to the innovative process. When each innovative factor is playing a role respectively and improving its efficiency, the synergy innovation is realizing value adding and value creation by mechanism innovation in the meantime [11].

Chinese Former President Jingtao Hu used to emphasize that the government should encourage universities to carry out in-depth cooperation with research institutions and corporations, and to form synergy innovation alliances by institution or mechanism revolution and policy guidance [12]. The idea of synergy innovation has brought a brand-new way for the construction of university experimental teaching platform. The university-enterprise co-building of experimental laboratories and centers can improve the teaching conditions, provide university experimental teaching with high-quality resources and offer the cultivation of applied talents a sharing platform [13].

Guangdong University of Finance (GDUF) is an applied university with distinct industrial characteristics. Under the guidance of advanced theory of university management, GDUF explored actively how to improve university characteristic development by experimental teaching. In order to meet the need of high-quality financial talents cultivation, GDUF introduced experimental teaching to financial talents cultivation without reservation, and created the experimental teaching mode of "single experiment - curriculum experiment - major comprehensive experiment - multi-major comprehensive experiment - multidisciplinary comprehensive experiment”. Because multidisciplinary research is an important approach to synergy innovation, only find the direction of multidisciplinary research can synergy innovation gain precondition. As a result, in order to develop a more practicable FERP experimental teaching platform and implement the strategy of synergy innovation, GDUF has collaborated and explored with Yonyou Network Co., Ltd., the biggest management software supplier in Asia-Pacific region, for seven years.

\section{PlatForm DESIGN IDEAS}

First of all, we start from demand for talents of financial corporations. The platform design follows the philosophy that " base on but be superior to current system”, blends into advanced financial corporation management theory and realizes the simulation of banking business and management process by modern information technology. Additionally, it takes the main working process of financial corporations and division talents standards into consideration. It tries to break the limits between traditional courses and designs multidisciplinary experimental projects.

Secondly, we combine with the talents cultivation goal of "Finance +" in GDUF. Majors of GDUF have gradually formed industrial demand-oriented talents cultivation modes. Its disciplinary construction reflects the "Finance +" feature sufficiently. Therefore, platform construction needs to support the applied talents cultivation goal and collaborate with outside corporations to co-develop the overall solution of financial experimental teaching environment.

Thirdly, we innovate experimental teaching technology and method. It is necessary to introduce advanced information technology to platform construction, realizing the electronization of experimental teaching and sharing of experimental teaching resources. The platform should satisfy students' needs of autonomous study, collaborative study, inquiry study and interactive study.

On this basis, our FERP Experimental Teaching Platform has formed the design ideas of " 4 innovation +1 source", as shown in Fig 1. The university-enterprise synergy innovation is the source of power that can form innovative forces by sharing resource and information. The teaching quality can be improved greatly after the innovation of experimental teaching ideas, experimental curriculum system, experimental organization pattern and experimental teaching environment, etc.

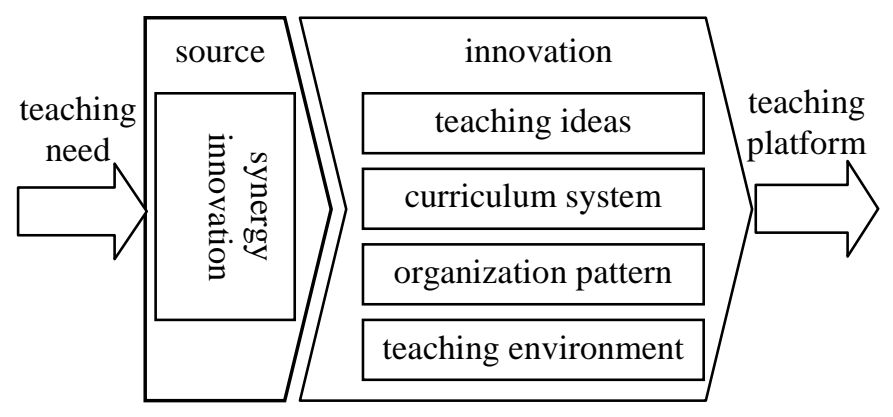

Fig. 1 Platform design ideas

\section{THE CONTENTS OF PLATFORM CONSTRUCTION}

\section{A. The Construction of Financial Corporation Panorama Emulational Experimental Teaching Platform}

Our FERP Experimental Teaching Platform introduces the management method of "Process Banking", blends into advanced financial management theory and method and realizes the simulation of internal management process of banks, helping students experience the real banking environment. As for teaching function design, our platform is constructed according to the principle of "Three Transverse Layers and Three Lengthways Layers”. Firstly, the plan is divided into knowledge layer, corporation layer and business layer breadthwise. Thus, the simulated experimental environment is able to realize the cognizing of professional knowledge, corporation and its environment. Secondly and lengthways, the simulation of important activities of banking 
business layer, management layer and strategy layer is realized. To be specific, it includes:

- Business layer simulation. Personal business, corporate business, investment and financing business, credit business, daily settlement business and bond business are included in this layer.
pricing(FTP) and relationship management are included in this layer.

- $\quad$ Strategy layer. Banking financial analysis, banking customer analysis, banking risk analysis, strategy analysis, strategy analysis and performance analysis are included in this layer.

- Management layer simulation. Banking financial management, risk management, human resource management, marketing management, funds transfer

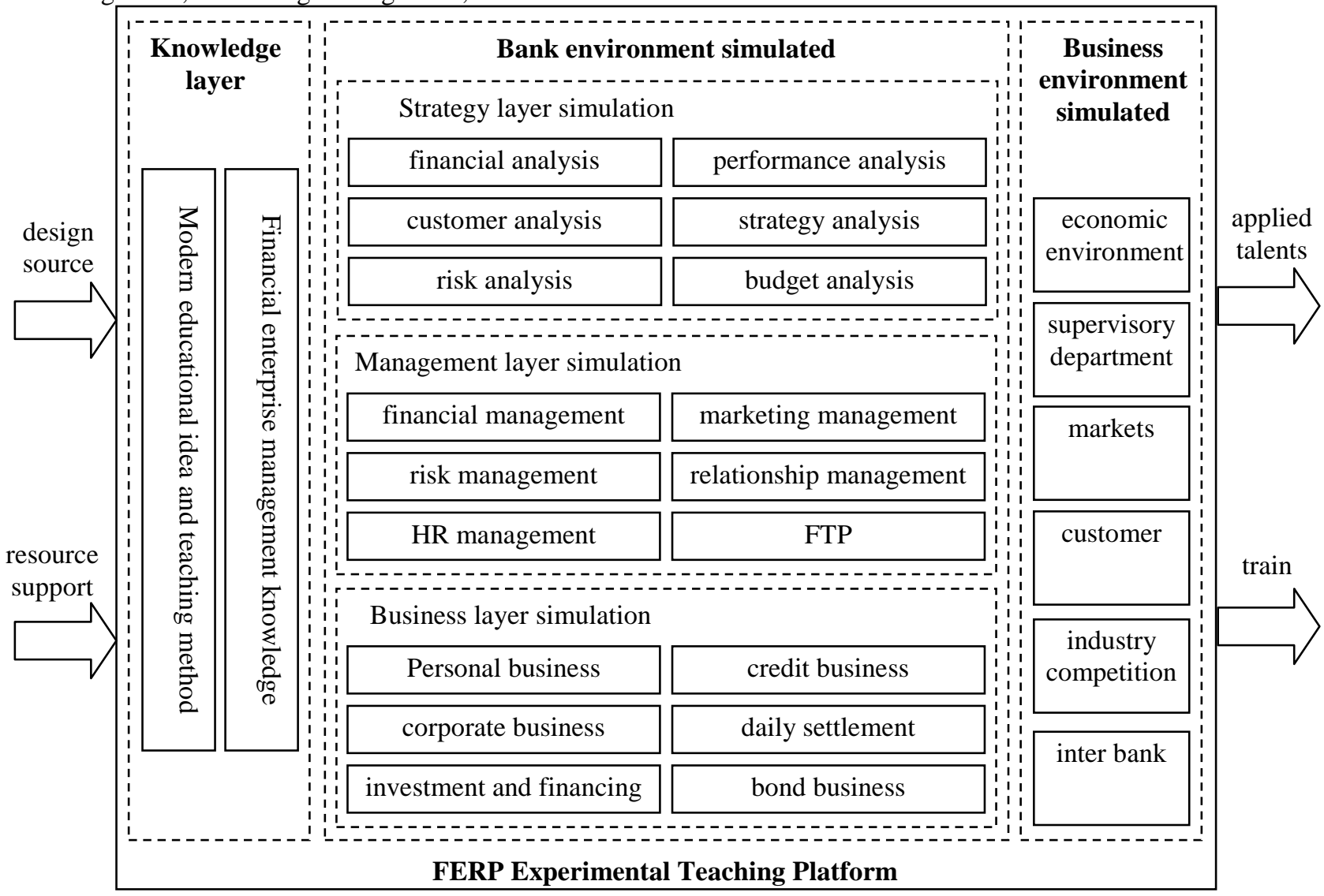

Fig. 1. FERP experimental teaching platform diagram

\section{B. The Construction of Complete FERP Experimental Curriculum System}

Our platform mixes finance, management and information technology together. It develops more than 50 multidisciplinary experimental projects with comprehensiveness, design, analyzability and research ability, involving asset transformation pricing, economic asset management and asset liability management, and built a hierarchical experimental teaching system, specific to students of economy and management specialty, which contains three levels "financial corporation cognizing", "professional comprehensive training" and "on-campus emulation internship”. The business process emulation system can help students to grasp the basic process of main business of financial corporations and form rudiments of financial corporation cognizing. The management process emulation system is mainly used to develop training of management positions, such as financial management, risk management, asset liability management and strategic management. The students get familiar with various management positions and improve their ability of applying professional knowledge by experiencing the banking management activities. The oncampus emulation internship provides students with the opportunities of experiencing the whole operating process of commercial banks, so they can establish the concepts of overall financial corporation and become familiar with the synergetic relationship inside corporations and the relationship between financial corporations and outside environment. Because of the high emulation and vivid experience of the experimental projects, the studying enthusiasm of students is motivated largely. 


\section{The Development of FERP Experimental Teaching Resources}

The teaching resources pool is composed of experimental guidance books, knowledge base, case base and problem sets. The writing of series of experimental guidance books emphasizes both theory and practice equivalently, making experiments close to reality. The knowledge base resolves the contradiction between experimental teaching and theoretical teaching effectively, and the efficiency of experimental teaching has been improved. The case base extends the experimental courses, and students can finish their experimental projects better by the inspiration of vivid cases. The problem sets helps students to increase their degree of proficiency by doing pre-class and after-class exercises.

\section{The Construction of Efficient "Team Synergy" Interactive Experimental Teaching Mode}

The teaching mode breaks the disciplinary restrictions to form experimental faculty and organize experimental teaching activities. The faculty consists of different teachers from finance department, business administration department, accounting department and laboratory center. All experimental projects get rid of the restrictions on disciplines and traditional administrative class. Students from different majors are divided into new experimental classes again, 49 to 56 students each, and 8 students form a team to work on projects together. Each team simulates one bank with the structure of "head office - subsidiary bank - branch - business department”. Each team member is playing one role, which can be either an administrative organization, such as head office and branch, or a functional department such as asset liability management department and human resource management department. This collaborative and exploring manner of study has motivated the enthusiasm, initiative and creativity of students greatly. What's more, the students share what they saw, thought and received during the experiments with each other, which benefits both the efficient completion of experiments and the cultivation of the ability of communication and the spirits of teamwork. According to the feedback from teaching assessment activities, most of the students think the FERP experimental teaching platform help them improve their ability of applying knowledge, innovating and working as a team.

\section{E. The Construction of Open, Sharing, Interactive and Collaborative Experimental Teaching Environment}

Openness and sharing are the most important characteristics of modern experimental teaching platform. Our FERP experimental teaching platform adopts the advanced B/S structural technology, so the users only need to install java plug-in on their computers to realize $7 * 24$ hours remote access to platform resources, including experimental teaching software and teaching materials. Therefore, the students can study FERP experimental courses not only at labs but also at their dormitories or even off campus. So far, the open and free learning environment has been reached. At the meantime, both teachers and students can take advantage of the built-in Elearning system to carry out network interactive study and collaborative study. This learning style changes students from passive listeners to active learners and changes classes from textbook-control to students-control. Students participate and explore actively in this virtual environment to construct their knowledge structure, improving their practical ability and comprehensive quality.

\section{CONCLUSION}

Firstly, university-enterprise synergy is an effective way to build high-level comprehensive experimental teaching platform. If universities aim to build high-level multidisciplinary comprehensive experimental teaching platform, it is necessary to collaborate closely with synergy corporations, adhere to the principles of joint development, take full advantage of technology, information, faculty and employment resources of synergy corporations, realizing total innovation of experimental teaching platform functions, curriculum system design, teaching mode revolution and teaching resources construction.

Secondly, the ownership of intellectual property of innovative accomplishments achieved by university-enterprise synergy must be clarified clearly in advance. During the process of co-construction of FERP experimental teaching platform, GDUF has not only invested capital but also organized teachers to design innovative experimental teaching functions. Our partner, Yonyou has finished system function development, coding development, database development and system implementation according to our demand. Lots of our innovative achievements are reflected in experimental teaching software finally in the form of demand, however, the software copyright belongs to Yonyou. Thus, how to protect the intellectual property of university is a new problem.

For the first time, our FERP experimental teaching platform studies on the cultivation of multidisciplinary talents in the financial industry systematically from the perspective of practical teaching, and constructs the knowledge, ability and quality centered multidisciplinary curriculum system. The platform has a brand new try in disciplinary construction, "Finance +" talents cultivation mode, experimental curriculum system, experimental teaching resources and multidisciplinary cooperation, realizing seamless connection between talents cultivation of university and talents demand of financial corporations. The project team fully explored the universityenterprise synergy construction of experimental teaching platform from theory to practice, providing successful guidance for university-enterprise synergy innovation and cultivation.

\section{ACKNOWLEDGMENT}

This work was supported in part by Education Department of Guangdong Province (Guangdong University Education Letter [2015]No.173, 460), and 2013 Central Finance Special Funds (KC109025). The authors thank Dr. Wenyuan Xiong for the valuable discussion. 


\section{REFERENCES}

[1] Mei Yu, Youbao Xi, Yun Liu , "Constructing a national representative center of laboratory education,and building a platform for training creative students,” Experimental Technology and Management, 2006, vol. 12, pp. 10-12(In Chinese)

[2] Xianjun Song, “The application prospect of virtual laboratory in university's experiment,” Experimental Technology and Management, 2005, vol. 22, pp. 35-37, 47(In Chinese).

[3] Kuanna Huang, Hui Liu, Muhua Li, "Information Technology-Based Teaching of Advanced Mathematics Test,” Journal Of Southwest China Normal Unibersity(Natural Science Edition), 2011, vol. 36, pp. 210215(In Chinese).

[4] Ansoff H I, Corporate Strategy: An Analytic Approach to Business Policy for Growth and Expansion, ew York: McGraw-Hill, 1965.

[5] Srivastava M K, Gnyawali D R, "When do relational resource matter? Leveraging portfolio technological resources for breakthrough innovation,” Academy of Management Journal, 2015, vol. 54, pp. 797810.

[6] Xiaodi Wang, Yan Xu, Siru Ren, "Review on the viewpoint of enterprise cooperative innovation research,” Economic Review, 2013, vol. 6, pp. 117-120(In Chinese).

[7] Gang Zhang, Jin Chen, Qing Xu, “The Coordinated Innovation Among Technology, Organi ation and Cultureinan Enterprise," Studies in Science of Science, 1997, vol.15, pp. 56-61(In Chinese).
[8] Yantin Rao, "Connotation, requirements and policy ideas of collaborative innovation of "combining learning with research and production,” Higher Education Exploration, 2012, vol. 4, pp. 29-32(In Chinese).

[9] Jin Chen, Yinjuan Yang, "Theoretical basis and content for collaborative innovation," Studies in Science of Science, 2012, vol. 20, pp. 161164(In Chinese).

[10] Zilong Wang, Qingmei Tan, Xiaodi Xu, "Strategy Alliance and its coordinative innovation model,” Management Review, 2006, vol. 3, pp. 59-62(In Chinese).

[11] Xuemei Xie, Leilei Zou, Siyu Liu, “Impact of Synergic Innovation Models of SMEs on Synergic Innovation Effect: Double-Moderating Effect of Synergic Mechanismand Synergic Environment,” Science of Science and Management of S.\& T., 2014, vol. 5, pp. 72-81(In Chinese).

[12] Jintao Hu, "Speech at the celebration of the 100th anniversary of Tsinghua,” People's Daily, 4th April 2011(In Chinese).

[13] Hui Xu, Hanqi Yu, Niansheng Yin, "On how to promote training application-oriented talent through laboratory plat orm jointly constructed by school-enterprise cooperation," Experimental Technology and Management, 2010, vol. 27, pp. 212-214, 217(In Chinese).

[14] Chuanhui Xue, "Collaborative Innovation in Institutions of Higher Education and Its Strategic Focus,” Journal of Higher Education Management, vol.6, pp. 24-28(In Chinese). 